\title{
On choosing the varietal type in consideration of the farmer's economic point of view
}

\author{
A Gallais 1, M Rives 2 \\ 1 INA-PG, 16, rue Claude-Bernard, F75231 Paris Cedex 05 \\ INRA-UPS, Station de Génétique Végétale, Ferme du Moulon, F91190 Gif-sur-Yvette; \\ 2 INRA, Station d'Amélioration des Plantes Maraíchères, BP 94, F84143 Montfavet Cedex, France
}

(Received 16 October 1992; accepted 22 July 1993)

\begin{abstract}
Summary - The choice of the varietal type that a farmer will use is the result of considering the balance between seed cost and the profit possible from using one type rather than another. This paper uses the criteria of quantitative genetics to predict the relative advantages of a population, lines extracted from this population, hybrids (3-way-, double-, and single-crosses) between such lines and their $F_{2} s$. Inbreeding depression, rate of multiplication, genetic variability, the ratio of seed price to grain value constitute the main parameters of comparison. There is no single answer to the question and even the situation for one species may evolve over time and accompanying progress in selection. The $F_{1}$ hybrids are the best type of variety in a large range of situations with high inbreeding depression $(>40 \%)$ and sufficient genotypic variance. In such a situation the expected superiority of single-cross hybrids over population is 20 to $35 \%$. For cross-fertilized species, populations are to be considered only for low genetic coefficients of variation for hybrids and a relatively high seed cost. $F_{2} s$ and lines are obviously justified only with low inbreeding depression $(<20 \%)$ and relatively low variation among hybrids.
\end{abstract}

varietal type / hybrid / line / population / seed cost

Résumé - Le choix d'un type de variété du point de vue de l'agriculteur. Le choix du type de variété que l'agriculteur utilisera est le résultat de la considération du bilan entre le coût de la semence et le profit additionnel qu'il peut espérer en utilisant un type de variété plutôt qu'un autre (en particulier le grain qu'il produit lui-même). Cet article utilise des résultats de la génétique quantitative pour prédire l'avantage relatif d'une population, de lignées tirées de cette population, des hybrides ( 3 voies, doubles, simples) entre de telles lignées et de leur $F_{2}$. La dépression de consanguinité, le taux de multiplication, la variabilité génétique, le rapport de prix de la semence et du grain sont les principaux paramètres des comparaisons. II n'y a pas de réponse unique, et même la situation pour une espèce peut évoluer dans le temps, avec le progrès de la sélection et la diminution de la variabilité génétique. Les hybrides simples sont le meilleur type de variétés dans un grand nombre de situations avec une forte dépression de consanguinité (> $40 \%$ ) et une variance génotypique suffisante. Dans une telle situation, la supériorité attendue des hybrides par rapport à la population est de 20 à $35 \%$. Pour les espèces allogames les populations ne sont jusitifées que si la variation génétique est faible et si le coût des semences hybrides est relativement très élevé. Les $F_{2}$ et les lignées ne sont évidemment justifiées que si la dépression est faible $(<20 \%)$ et si la variation entre hybrides est faible.

type de variété / variétés hybrides / lignées / populations / coût des semences 


\section{INTRODUCTION}

The choice of a varietal type as a plant breeding aim can be considered from a purely genetic standpoint; it can also be considered from the economic aspect, and more specifically, from the farmer's point of view. From the genetic point of view, this problem has often been discussed in classical plant breeding literature. It is only necessary in the latter case to consider the difference in yield or in economic value of the product. From the farmer's point of view, however, as pointed out by Berlan (1983), one must also consider the impact of the cost of seed used for production on the overall return to the farmer. Berlan and Lewontin (1986) have claimed that the choice of hybrids has been forced on American farmers because they provided a source of profit for the (capitalist) plant breeding companies, owing to the farmer being obliged to purchase new seed every year, and that plant population breeding (by public institutions) would have yielded the same results while retaining the possibility for the farmer to produce his own seed. Note that this is approximately the basis of the policy adopted by international agricultural research centers such as the CIMMYT in their breeding programs for maize.

It is clear that the varietal type has a marked influence on seed cost. For example, in crossfertilized species, the seed of a single-cross hybrid will generally be more expensive to produce than that of a 3-way or a double-cross hybrid; and seed from hybrid varieties, whatever their type, is more expensive than that from an $F_{2}$ or from a population. Furthermore, for some varietal types, the farmer can produce his seed himself, especially with grain crops (eg, seed from populations, lines, $F_{2} s$, etc), although at the cost of obtaining a lower yield. The problem is then to determine which is the more economical procedure for the farmer: buying expensive seed of high yielding varieties, buying cheaper seed, or producing the seed himself, with a somewhat lower yield prospect. This question is all the more relevant as it highlights the latent conflict between the interests of the breeder and the farmer.

The aim of this paper is therefore to examine some genetic and certain economic considerations in an attempt to determine the optimal varietal type for the farmer. To achieve this, the margin (ie gross income minus direct charges) associated with a given varietal type will be con- sidered. A type 1 variety will be more profitable for the farmer than a type 2 variety, if:

$$
Y_{1} p_{g}-C_{1}>Y_{2} p_{g}-C_{2}
$$

where $Y_{1}\left(Y_{2}\right)$ is the yield for varietal type 1 (type 2), $p_{g}$ is the selling price of the product to be harvested and $C_{1}$ and $C_{2}$ are the charges associated with each varietal type. However, only charges dependent on the type of varieties need to be considered; these are the associated costs for seed, fertilizers and pesticides. Then, relationship [1] can be written as:

$$
p_{g}\left(Y_{1}-Y_{2}\right)>\left(C_{S 1}+C_{f 1}+C_{p 1}-C_{S 2}-C_{f 2}-C_{p 2}\right) \text { [2] }
$$

where $C_{S i}, C_{f i}, C_{p i}$ with $i=1$ or 2 respectively represent the cost of seed, fertilizers and pesticides. Considering only the effect of the varietal type, there is no reason to assume that requirements regarding a pesticide will be different depending on the varietal type (note that even if hybrid wheat is more resistant to certain diseases, it is quite possible to develop lines as resistant as hybrids). Then we consider $C_{p 1} \approx C_{p 2}$. For fertilizers it will be also considered that over a certain range of difference in yield $(\approx 20 \%)$ the farmer does not adapt fertilization to the yield then $C_{f 1} \approx C_{f 2}$. If he does, then the cost of the fertilizer could be integrated in a corrected selling price, $p_{g}^{\prime}$. However, it is clear that in relative value the difference in the farming cost of the 2 varietal types will be mainly due to the difference in the cost of the seed, even if the approximations just made are not fully satisfied. This means that $\left(C_{p 1}-C_{p 2}\right)$ and $\left(C_{f 1}-C_{p 2}\right)$ can generally be relatively small in comparison to $\left(C_{\mathrm{s} 1}-\right.$ $C_{\mathrm{s} 2}$ ). Then with such assumptions, expression [2] becomes:

$$
p_{g}\left(Y_{1}-Y_{2}\right)>d_{1} p_{1}-d_{2} p_{2}
$$

or after rearrangement to make the relative difference in yield of the 2 varieties explicit, and with $d_{2}=\delta d_{1}$ and $Y_{1} / d_{1}=t_{1}$ being the multiplication rate

or

$$
\begin{aligned}
& \left(Y_{1}-Y_{2}\right) / Y_{1}>\left(p_{1}-\delta p_{2}\right) /\left(p_{g} t_{1}\right) \\
& \left(Y_{1}-Y_{2}\right) / Y_{1}>\left(r_{1}-\delta r_{2}\right) / t_{1}
\end{aligned}
$$

where $r_{1}$ and $r_{2}$ are relative prices in terms of harvested grain prices.

This expression is a generalization of that given by Gallais (1989) in a study of the justification 
of $F_{2}$ seeds in comparison to $F_{1}$. It shows that the difference in sowing rate can be integrated in the difference in the cost of the seeds by defining $r_{2}^{\prime}$ $=\delta r_{2}$. Fundamentally the relative advantage of a given type 1 variety over another type 2 depends upon 2 parameters: $\left(r_{1}-r_{2}^{\prime}\right)$, which is the difference between the relative seed costs (equivalent value in harvested seed) and $t_{1}$, the multiplication rate.

Expression [3] will be used to discuss under which conditions a given varietal type will be superior - from the economic point of view - to another. Considering only the case of sexually propagated varieties, and excluding that of synthetics as already discussed by Gallais (1990a, 1992), the following comparisons will be developed: hybrids vs lines; hybrids vs population and $\mathrm{F}_{1}$ hybrids vs $\mathrm{F}_{2} s$; lines vs population and lines $v s \mathrm{~F}_{2} s$.

\section{HYBRIDS VS LINES}

Let hybrids $(H)$ represent type 1 and lines $(L)$ type 2; then according to expression [3], for there to be an economic advantage for hybrids it would be necessary:

$$
\left(Y_{H}-Y_{L}\right) / Y_{H}>\left(r_{H}-r_{L}\right) / t_{H} .
$$

Gallais (1989) has studied the conditions for $\left(Y_{1}-Y_{2}\right) / Y_{2}>0$, ie, for the best hybrid to be superior to the best lines. The same reasoning can again be used to solve:

$$
\left(Y_{H}-Y_{L}\right) / Y_{H}>\left(r_{H}-r_{L}\right) / t_{H}
$$

where $Y_{H}$ is replaced by the value of the best possible single crosses (MaxSC) from a population and $Y_{L}$ by that of the best possible lines (MaxL) from the same population. Then, considering only the distribution of genetic values for both types of varieties, it is possible to write:

$$
\left[\left(m_{H}+i \sigma_{H}\right)-\left(m_{L}+i \sigma_{H}\right)\right] / m_{H}>\left(r_{H}-r_{L}\right) / t_{H}
$$

where $i$ is the theoretical selection intensity among varieties of a given type, assuming it to be the same for both types, $m_{H}$ is the mean of all possible single crosses from the population (in the absence of epistasis, it is also the mean of the random mating population), $m_{L}$ is the mean of all possible lines that can be derived from the population, $\sigma_{H}^{2}$ is the genetic variance among all possible single crosses, and $\sigma_{L}^{2}$ is the genetic variance among all lines that can be derived from the population. The expression can be simplified, and the hybrids are justified when:

$$
\Delta>i C_{H}\left(Q_{L H}-1\right)+\left(r_{H}-r_{L}\right) / t_{H}
$$

where $\Delta$ is the maximum inbreeding depression in relative value: $\Delta=\left(m_{H}-m_{L}\right) / m_{H}, C_{H}$ is the genetic coefficient of variation for single-cross hybrids $\left(\sigma_{H} / m_{H}\right), Q_{L H}$ is the ratio $\sigma_{L} / \sigma_{H}$.

For the parameters of [4], we can take the following as realistic values: $Q_{L H}$ : between 1 and 2; $Q_{L H}$ is expected to be $\sqrt{2}$ in the case of strict additivity; $C_{H}$ : between 0.05 and 0.20 according to Hallauer and Miranda (1981);

$\Delta$ : between 0.00 and 0.70 ;

$i$ : between 2 when the selection rate is $5 \%$ and 3 when it is $0.35 \%$;

$\mathrm{t}$ : between 40 and 50 for wheat and between 300 and 400 for maize.

The ratios $r_{H}, r_{L}$ vary according to the economic situation in the various countries. In France for a cross-fertilized species like maize, the ratio of the cost of hybrid seeds $\left(p_{H}\right)$ to the selling price of harvested grain $\left(p_{g}\right)$ is $\approx 30-40$. For a self-fertilized species like wheat the ratio $\left(p_{L} / p_{g}\right)$ is of the order of 3 when the farmer renews his seeds, and nearly 1 when he uses harvested grain as seeds.

To illustrate the justification of hybrids in comparison to lines let us consider 2 extreme situations, ie those of maize and wheat. Obviously the consideration of lines in cross-fertilized plants like maize is only for the sake of generality.

For maize we may take $\Delta=0.60, C_{H}=0.10$, $Q_{L H}=1.4(\sqrt{ } 2), i=2.5, t_{H}=300, \mathrm{r}_{H}=p_{H} / p_{g}=30$. If we agree to take $p_{L} / p_{g}=1$ as with wheat, then $\left(p_{H} / p_{g}-p_{L} / p_{g}\right)=29$, and thus $\left(r_{H}-r_{L}\right) / t_{H}$ is $\approx$ 0.10 . As expected, with such values [4] indicates a strong advantage for single-cross hybrids.

For a self-fertilized species such as wheat we can take $\Delta=0.10$, again with $C_{H}=0.10, Q_{L H}=$ $1.3, i=2.5$; in this case, we have seen that $p_{L} / p_{g}$ $=1$ to 3 according to whether or not the farmer renews his seed, and we are looking for values of $p_{H} / p_{g}$ that will put hybrids at an advantage over other strategies. Incorporating the above values into [4] it then becomes:

$$
0.10>2.50 .10(1.3-1)+\left(p_{H} / p_{g}-3\right) / 30
$$

or: $p_{H} / p_{g}<3.75$ for $p_{L} / p_{g}=3$

and: $p_{H} / p_{g}<1.8$ for $p_{L} / p_{g}=1$. 
As it is probable that the cost of hybrid seed will be increased $>25 \%$ in comparison to presently certified seed, it ensues that the use of single-cross hybrid varieties for wheat would not be profitable for the farmer. This is due to the fact that in this situation it is possible to counterbalance by selection the negative effect of a relatively small inbreeding depression. In such as case, it will be easy to develop lines with performances nearly equal to those of single-crosses, using an appropriate recurrent selection method such as that of the single- doubled-haploid recurrent selection (SDHRS: Gallais, 1988, 1989, 1990b; Gallais and Fouilloux, 1988). As a consequence, it is possible to predict that the future of hybrid wheat is not very clear. Indeed with wheat, the cost of seed must be kept as low as possible. Moreover, even though heterosis could be increased by selection, at the same time so would the value of the lines from the population.

Finally, the main parameter on which it is possible to act is the sowing rate (d). As a matter of fact, it would be feasible to decrease $d$ by decreasing the weight of individual seeds while keeping plant stand constant through sowing smaller seeds. This would be feasible if it were possible to breed varieties with small kernels and the same yielding potential as with heavykernel varieties. This is exactly what INRA did with a different subject but a parallel situation, ie with the "Vedette" hybrid breed of meat chickens, in which the female parent line carried a gene for dwarfism and the cock transmitted its dominant normal size to the commercial progeny generation. It is interesting to note that the maize seed industry has responded to this possibility by selling maize seed by the "thousand viable seeds" (MGV for "mille grains viables" in French).

\section{HYBRIDS vs POPULATIONS}

Since the early work by Shull (1908) following the rediscovery of Mendel's laws, it has been clear that a random mating population can be considered as a mixture of single-cross hybrids. Assuming no interaction among genotypes (absence of allo-competition, but possible autocompetition, ie effects of density) it is clear that the best population will always be inferior to the best single-cross hybrid. With the assumption of no allo-competition effects, a mixture of various constituents cannot be better than the best con- stituent: it will be equal to the average of all constituents. In presence of allo-competition however, the mixture will generally be better than the average of all constituents. Then if homogeneity is not necessary, such a mechanism will reduce the difference between the best hybrids and the population.

The level of the population could be improved through recurrent selection and also that of the best single-cross hybrid. Hence from a strictly genetic point of view the problem is clear. From the economic point of view, ie in the present study from the farmer's point of view, the problem lies in whether the superiority of the singlecross hybrid will be sufficient to prompt the farmer to buy $F_{1}$ seed instead of producing his own seed from the population. From [3], with hybrids $(H)$ for type 1 and population $(P)$ for type 2, this will be the case if:

$$
\left(Y_{H}-Y_{P}\right) / Y_{P}>\left(r_{H}-r_{P}\right) / t_{H}
$$

$Y_{H}\left(Y_{P}\right)$ being respectively the yield of the best $F_{1}$ hybrid and the yield of the population.

Note that in the situation considered, $p_{P}$ is approximately equal to $p_{g}$ and then $\left(p_{H}-p_{P}^{\prime}\right) / p_{g} \sim$ $p_{H} / p_{g}-1$. Incorporating genetic considerations one can write: $Y_{H}-Y_{P}=i \sigma_{H}$ where $i$ is a theoretical selection intensity and $Y_{P}=m_{H}$.

Then [5] becomes:

$$
i C_{H}>\left(r_{H}-r_{P}\right) / t_{H} \text { or } i>\left(r_{H}-r_{P}\right) / C_{H} t_{H}
$$

Taking as an example the case of maize, it has previously been considered that $p_{H} / p_{g} \sim 30$, $t_{H}=300$; with $C_{H} \# 0.10$ it is clear that $i$ can easily be $>1$; hence with such values for the parameters, hybrids will be more desirable to the farmer than the population. For their attractiveness to decrease, it will be necessary for $C_{H}$ to be as low as 0.06 , which means that the genetic variance would have to be relatively low. This can also happen if the cost of hybrid seed increases.

One should note that the expected superiority of the best single crosses (Max $S C$ ) can be predicted by:

$\operatorname{Max} S C=m_{H}+i \sigma_{H}$, or:

$\operatorname{Max} S C=m_{H}\left(1+i C_{H}\right)$,

so that with $i=2$ and $C_{\mathrm{H}}=0.10$, the best singlecross hybrids will be $20 \%$ superior to the population. As $i$ can hardly be $>3$ (this value corresponds to a rate of selection of $0.3 \%$ ), the maxi- 
mum difference could be $30 \%$. Indeed, in maize some results indicate a $20-30 \%$ genetic advance as due to the development of single-cross hybrids.

It is also interesting to consider the expected advantage of double or 3-way cross hybrids, as historically they were developed first. Interestingly, it was only to overcome the poor yield and seed quality of the early inbred lines that Jones (1918) invented the process of double-crossing, ie using a single cross for producing commercial seed in order to decrease the cost of seed, which was an implicit early illustration of the empirical application of the very principles developed here. Obviously the best double crosses or the best 3way crosses are inferior to the best single-cross hybrids. In the absence of epistasis and with a dominance variance equal to the additive variance, the following relationships exist among genetic coefficients of variation and can be drawn (in the MS) from table I:

$C_{D C}=0.61 C_{S C}$

$C_{T W C}=0.79 C_{S C}$

where $C_{S C}, C_{D C}, C_{T W C}$ are genetic coefficients of variation for single crosses, double crosses and 3-way crosses respectively. Then for a superiority of $20-30 \%$ of single crosses over the population, the superiority of 3-way crosses is expected to be $16-24 \%$; that of the double crosses is expected to be $12-18 \%$.

With the previous assumption on variance components and considering the case of doublecross hybrids, [6] becomes:

$$
i>\left(r_{H}-r_{P}\right) /\left(0.61 C_{H} t_{H}\right)
$$

That is to say, for the values considered for maize $\left(C_{H}=0.10, t_{H}=300, r_{H}-r_{P} \sim 30\right), i>$ 1.64; such a value for $i$ corresponds to a selection rate of $\approx 12 \%$. Generally $i$ will be $>1.64$; thus on the average double crosses will be also more profitable for the farmer than the population, and their advantage must be still clearer if one considers that the relative seed cost $p_{H} / p_{g}$ must be lower for double crosses than for single crosses. This means that one must consider that $\left(r_{H}-r_{P}\right)<30$. However, this change is relatively small.

As a consequence of the relatively low advantage of double crosses in comparison to populations, and considering that following Shull's work the first commercialized hybrids were poorly selected double crosses, it can be deduced that these first hybrids were not such a source of additional profit to the farmer. A small decrease or a stagnation in corn yields was observed coinciding with the development of the first hybrids. One wonders whether the 2 events are related. As a matter of fact, the first maize hybrids sold commercially, eg, by Funk's in 1929, were poorly adapted to most of the areas in which they were sown; and to make things worse, the early thirties happened to be years of extremely bad weather and parasitic conditions, in which the hybrids performed very poorly (Fitzgerald, 1986). Berlan's studies (1983), raise the question of how the development of the hybrids was possible. There seems to have been a political decision within the USDA around 1920 to switch selection toward breeding hybrid varieties. It may have been prompted by the wish to end with the "best corn ear contests" which provided profits for the prize-winning farmers - and for

Table I. Expression of mean and variance of different types of varieties $\left({ }^{\star}\right)$ in the absence of epistasis.

\begin{tabular}{lll}
\hline Varietal type & Mean & Variance \\
\hline Population & $m_{H}$ & \\
Single-cross hybrids & $m_{H}$ & 0 \\
Three-way-cross hybrids & $m_{H}$ & $\sigma_{H}^{2}=\sigma_{G}^{2}=\sigma_{A}^{2}+\sigma_{D}^{2}$ \\
Double-cross hybrids & $m_{H}$ & $3 / 4 \sigma_{A}^{2}+1 / 2 \sigma_{D}^{2}$ \\
Lines & $m_{L}=m_{H}(1-\Delta)$ & $1 / 2 \sigma_{A}^{2}+1 / 4 \sigma_{D}^{2}$ \\
$F_{2}$ & $m_{H}(1-\Delta / 2)\left(^{*}\right)$ & $\sigma_{L}^{2}=2 \sigma_{A L}^{2} \sim 2 \sigma_{A}^{2}+f(D)$ \\
& & $\sigma_{F_{2}}^{2} \sim \sigma_{A}^{2}+1 / 4 \sigma_{D}^{2}+f^{\prime}(D)$
\end{tabular}

$\left(f(D)\right.$ and $f^{\prime}(D)$ are linear combinations of variance components due to inbreeding and involving dominance effects at a homozygous level (Gallais, 1989). 
the members of the jury panels, but did nothing toward improving the corn populations and the farmer benefit. Eventually, the development of better double crosses (Fitzgerald, 1986) and later of 3-way crosses and more recently, of singlecross hybrids, provided hybrid varieties with a clear advantage that was reinforced by the beginning of land freezing that worked as an incentive to seek higher productivity. This advantage will last at least as long as there is sufficient genetic variability. On the other hand, the emergence of single-crosses seems to be a unique and remarkable result of the demands from the farmers, as opposed to the supply by the seed industry. They favored single-cross hybrids, because their uniformity in the stands made harvesting with corn-pickers possible. If they had used combines instead, this might not have been the case (Bogue, 1986). Farmers were prepared to pay more for the higher cost of seed when produced on an inbred female line. It is worth noting that this prompted the industry to breed female inbred lines combining the good combining ability of university lines with a high yield (see Duvick, 1974). (This is another example of how advantages other than increased yield may favor a varietal type, when the additional cost of the seed is compensated by savings from other sources.) The production of hybrid seed by the farmers was contemplated in the early days, and winter schools were held to instruct them on how to do this (Sprague, 1980). According to Fitzgerald (1986), "while in 1931 it seemed plausible for farmers to do their own hybridzing with university inbreds, by 1940 the idea was all but dead".

Were genetic variability to be reduced significantly (say by $\approx 50 \%$ ) it could then be more beneficial for the farmer to use the breeding population on condition that he had access to it. In this case it would not be profitable for the breeder to develop hybrid varieties. It would be sufficient to select for improving the per se value of the population, provided that he could protect the populations or persuade the farmer to buy new seed from the improved population frequently enough to guarantee him some profit.

Note that even if it were more profitable for the farmer to use the breeding population, and even if he were using mass selection to improve or maintain it himself, it would be advantageous for him to periodically renew his seed. Indeed, the efficiency of mass selection is restricted when heritability is low, and population improvement is higher when more sophisticated breeding strategies are adopted, such as family selection, prog- eny tests, etc (which cannot be used by the farmer, but only by the breeder). This constitutes the justification for the specific activity of a plant breeding industry, which may be public or private depending on the political and economic policy adopted. For the private breeding industry, however, it is barely feasible to release a breeding population. To make it profitable, the development of hybrid varieties, mainly of single crosses, with a steady renewal of seed from the farmer is a necessity: this leads to narrow-based homogeneous superior varieties that can pass the registration and protection tests, at least in Europe. The 'obligation' for the farmer to renew his seed every year provides the funding for plant breeding activity and stimulates genetic advance. Since the development of 3-way and single-cross hybrid varieties, the farmer has largely benefited from such as strategy. Thus one can see the development of double crosses as a transitory period, with double crosses which are at least as good as the population that opened the way for the 3-way and the single-cross varieties.

Another point is to also consider heterosis between populations: the cross between 2 complementary populations can be superior to both populations or to the random mating population derived from a mixture of the 2 populations. Indeed, this is what Beal (1880) had shown, as reported by Zirkle (1952). This was even commercially exploited by Funk's Seed in Illinois at the begining of the century (Fitzgerald, 1986).

\section{USING $F_{2}$ SEED}

\section{$F_{2}$ or $F_{1}$ seed?}

Using $F_{2}$ seed will be more profitable for the farmer in comparison to using $F_{1}$ seed when:

$$
\Delta_{S}<\left(r_{H}-r_{\mathrm{F} 2}\right) / t_{H}
$$

$\Delta_{s}$ being the inbreeding depression from $F_{1}$ to $F_{2}$ $\left(\Delta_{s}=\Delta / 2\right.$ in the absence of epistasis). With maize, according to the values given previously, $p_{\mathrm{F} 1} / p_{g} \sim 30, r_{\mathrm{F}_{2}}<2$, then $\left(r_{H}-r_{\mathrm{F}_{2}}\right) / t_{H} \sim 0.10$, and as the inbreeding depression is $>0.10$, clearly it is not advantageous for the farmer to use $F_{2}$ grain as seed. Even with a relative cost of $F_{1}$ seed twice the value considered here, it will be in the interests of the farmer to renew his seed. With wheat, taking $\left(r_{H}-r_{\mathrm{F} 2}\right) / t_{H}=0.10$, and as 
the inbreeding depression from $F_{1}$ to $F_{2}$ will be $<10 \%$, clearly it will be more economical for the farmer to use $F_{2}$ grain as seed. This is another reason that will slow down the development of hybrid varieties in wheat.

\section{$F_{2}$ seed or population?}

Obviously when inbreeding depression is sufficiently large, there is nothing to be gained by using $F_{2}$ instead of the population, and it is highly likely that the yield of the best $F_{2}$ will be inferior to that of the breeding population. It is worth noting that an $F_{2}$ is similar to a 2-parent synthetic. Gallais (1990a) has already shown that the gain from the selection of synthetics is generally low in comparison to the breeding population, except with low inbreeding depression and a low number of parents. The value of the best $F_{2}$ :

$$
\operatorname{Max}\left(\mathrm{F}_{2}\right)=m_{H^{-}}(\Delta / 2) m_{H}+i \sigma_{\mathrm{F}_{2}}
$$

will be larger than the value of the population when:

$$
i \sigma_{\mathrm{F}_{2}}>(\Delta / 2) m_{H}
$$

or:

$$
\left.i C_{\mathrm{F}_{2}}>\Delta / 2 \text { (with } C_{\mathrm{F}_{2}}=\sigma_{\mathrm{F}_{2}} / m_{H}\right) \text {. }
$$

Assuming a value of the $F_{2}$ seed larger than the selling price of the grain harvested, condition [8] becomes:

$$
i C_{\mathrm{F}_{2}}>\Delta / 2+\left(p_{\mathrm{F}_{2}} / p_{g}-p_{p} / p_{g}\right) / t_{\mathrm{F}_{2}}
$$

However, as $t_{\mathrm{F}_{2}}$ is relatively large (even if it is inferior to that for single cross) the ratio $\left(r_{\mathrm{F}_{2}}-r_{\mathrm{P}}\right) /$ $t_{\mathrm{F}_{2}}$ will be small in comparison to $\Delta / 2$ even if $p_{\mathrm{F}_{2}}$ is assumed to be twice $p_{g}$. Then with $C_{\mathrm{F}_{2}}=0.10$ $\left(C_{\mathrm{F}_{2}}\right.$ will generally be justified if $\left.\Delta<0.50\right)$, whereas when $\Delta>0.50$, it will not. In the first situation, however, the superiority of the $F_{2}$ will be very small: for example, with $\Delta=0.40$, the gain will be only $5 \%$, and with $\Delta=0.20$, a favorable situation, it will be $15 \%$.

It must be noted that there will be some risks to use advanced generations from the $F_{2}$. Then to have $F_{2}$ seeds, it is necessary to buy $F_{1}$ seeds every 2 yr. Strategy $F_{1}$ one year, $F_{2}$ the second year will be better than using the population if:

$$
i \Delta_{C}(2-\Delta / 2)>\Delta / 2+\left(r_{H}-r_{P}\right) / t_{H}
$$

which is verified when $i=2.5,\left(r_{H}-r_{P}\right) / t_{H} \sim 0.10$ $C_{H}=0.10$ for $\Delta<0.62$.

\section{LINES VS POPULATION AND LINES VS $F_{2}$}

The population considered is the random mating population. Then, such comparisons have meaning for semi-allogamous crops only, that is to say for partially cross-fertilized species with relatively low inbreeding depression such as eg rapeseed. The comparison 'lines vs population' has little meaning for self-fertilized crops. It will be assumed that the cost of seed is the same for a given comparison, because the farmer can reproduce both types of varieties. A specific cost of $F_{2}$ seed could be taken into consideration as when $F_{2}$ seed is purchased every other year, for example.

\section{Lines vs population}

If it is assumed that there is no additional cost for line-variety seed over the population, the best lines will be superior when:

$$
\begin{aligned}
& m_{L}+i \sigma_{L}>m_{H} \\
& i \sigma_{L}>m_{H}-m_{L} \text { or } i C_{L}>\Delta(1-\Delta)
\end{aligned}
$$

that is to say, if selection can overcome inbreeding depression. The genetic coefficient of variation among lines $\left(C_{L}\right)$ is likely to be larger than the CV among single crosses; it will also depend on inbreeding depression:

$$
C_{L} \approx Q C_{H}(1-\Delta)
$$

Then condition [10] will be approximated by:

$$
i Q C_{H}>\Delta \text {. }
$$

With realistic values $\left(i=2, Q=1.5, C_{H}=0.10\right)$, it can be seen that lines could be envisaged if inbreeding depression is $<0.30$. However, the gain will be relatively low. For example, assuming $\Delta=0.20$, with the previous set of values, the superiority of the best $5 \%$ lines over the population will be $10 \%$. The first variety of rapeseed to be selected as a pure inbred line (Rives, 1954), Sarepta, was $\approx 15 \%$ superior to existing populations at the time. 
When a specific cost has to be considered for the seed of the lines, the condition becomes:

$Y_{L}-Y_{P}>d\left(r_{L}-1\right)$ where $r_{L}=p_{L} / p_{g}$ or:

$i \sigma_{L}>\Delta m_{H}+d\left(r_{L}-1\right)$ where $r_{L}>1$

$i Q C_{H}>\Delta+\left(r_{L}-1\right) / t_{L}$.

Clearly, the higher the cost of line seed, the smaller the advantage of the lines. With the previous example, with $Q=0.20$ and with $\left(r_{L}-1\right) / t_{L}$ $=0.10$ (the approximate value for wheat in France), there will be no advantage with the lines.

\section{Lines vs $F_{2} s$}

From a genetic point of view, lines will be superior to $F_{2} s$ when:

$$
\begin{aligned}
& m_{L}+i \sigma_{L}>m_{H}-(\Delta / 2) m_{H}+i \sigma_{F_{2}} \text { or } \\
& i\left(\sigma_{L}-\sigma_{F_{2}}\right)>(\Delta / 2) m_{H} .
\end{aligned}
$$

With a simplifed model, $\sigma_{\mathrm{F}_{2}} \approx \sigma_{H}$ and $\sigma_{L}=1.41$ $\sigma_{H}$; then [11] becomes:

$$
0.41 i C_{H}>(\Delta / 2) \text {. }
$$

Then with $i=2$ and $C_{H}=0.10, \Delta$ must be inferior to 0.16 . With a specific cost of seed for lines, [11] becomes:

$$
i\left(\sigma_{L}-\sigma_{\mathrm{F}_{2}}\right)>(\Delta / 2) m_{H}+d\left(r_{L}-1\right)
$$

and with the same set of parameters as previously:

$$
0.41 i C_{H}>(\Delta / 2)+\left(r_{L}-1\right) / t_{L} .
$$

Obviously this diminishes the attractiveness of lines. With $r_{L}=2.75$ as previously, $t_{L}=35,\left(r_{L}-\right.$ $1) / t_{L} \sim 0.08$, this completely suppresses the advantage of lines.

\section{CASE OF CERTIFIED SEEDS}

The same line of reasoning can be used to determine when it is beneficial for the farmer to renew his seed for self-fertilizing crops. New seed (ie certified seed) will be advantageous when the average yield from this seed $\left(Y_{N}\right)$ in comparison to the yield $Y_{O}$ of 'old' (non-certified) seed will be:

$$
Y_{N}-Y_{O}>d\left(r_{N}-1\right) \text { or } \Delta_{C}>\left(r_{N}-1\right) / t
$$

$\left(\Delta_{C}\right.$ being here the relative lost in yield by the use of non-certified seed).

Clearly in the case of wheat, it is difficult to conceive that $\Delta_{C}=\left(Y_{N}-Y_{O}\right) / Y_{N}>5 \%$. Then, assuming $t=35,\left(r_{N}-1\right)$ ought to be inferior to 1.75 , or $r_{N}=p_{N} / p_{O}=2.75$. This considerably restricts the seed producer's margin. From the point of view of the farmer certified seeds has the advantage of security (genetic and physiologic quality of seed) a criterion which has not been considered in our approach.

The difference between the cost of the grain as seed and the grain as product may come from the farmer's taking into consideration criteria that are not of a genetic nature, but pertain to the quality of the seed per se: seed "conditioning", ie screening and coating with pesticides, carried out on farmer's grain either by the farmer himself or by specialized companies is an example; this has been fought against by the plant breeding companies as it threatens their profit, in spite of the "farmer's privilege clause" (of using his own grain as seed for protected varieties) contained in the protection law.

\section{DISCUSSION AND CONCLUSION}

From these considerations, it is possible to determine the domain of justification of each type of variety. Table II summarizes the conditions for the superiority of a given type in comparison to others. With the assumptions made, there are 6 types of parameters to take into account:

- the genetic coefficients of variation $\left(C_{H_{1}}, C_{\mathrm{F}_{2}}\right.$, $\left.C_{L}\right)$;

- inbreeding depression, $(\Delta)$;

- the ratio $Q\left(\sigma_{L} / \sigma_{H}\right)$;

- the rate of multiplication $t_{H}$ which for a given species could be related to inbreeding depression, for example $t_{L}=(1-\Delta) t_{H}, t_{F_{2}}=\left(1-\Delta / 2-t_{H}\right)$;

- the ratio of the cost of both seed types according to the comparison. This incidentally provides the possibility of including here all factors that are not of a genetic nature, such as seed dressing, homogeneity of the crop that influences the harvested yield, that have been mentioned above. It is justified to assume that the cost of $F_{2}$ seed, seed from a line variety and seed from a population are of the same order (because they 
have the same status, ie they can be selfreproduced by the farmer) $r_{\mathrm{F}_{2}} \sim r_{L} \sim r_{P}=r_{o}$ ). We have also considered that $\sigma_{\mathrm{F}_{2}} \sim \sigma_{H}$. This simplifies inequalities given in table $\|$ and reduces to 4 the previous parameters involved in the comparison of the 4 types of variety $F_{1}, F_{2}$ line, population: $C_{H}, \Delta, Q$ and $\left(r_{H}-r_{O}\right) / t_{H}$;

- the selection intensity $i$ is fixed at 2 , ie a selection rate of $\approx 5 \%$. A value of 2.5 , ie a selection rate of nearly $1 \%$ has also been considered in some comparisons. Such a value is difficult to estimate because the selection is not generally developed among varieties, but in several steps. It can seem higher than the values considered but this is not obvious because many factors, some controlled, some uncontrolled, affect the development of a variety; thus the effective selection intensity must be lower than a priori expected.

The 4 parameters $\left(C_{H}, Q, \Delta\left(r_{H}-r_{0}\right) / t_{H}\right)$ are the more critical. Fixing 2 parameters out of 4,6 representations can be presented:

$f\left(C_{H}, \Delta\right):$ for $Q$ and $\left(r_{H}-r_{o}\right) / t_{H}$ fixed;

$f\left(C_{H}, Q\right)$ : for $\Delta$ and $\left(r_{H}-r_{0}\right) / t_{H}$ fixed, etc.

Figure $1 \mathrm{a}-\mathrm{f}$ presents these results.

As expected, when inbreeding depression is strong $(\Delta>0.40)$, hybrids will be the best type of variety, and in this situation $F_{1}$ hybrids $>$ population > lines (fig $1 \mathrm{~b}, \mathrm{~d}, e$ ). Obviously this is only valid for realistic genetic coefficients of variation for the hybrids. The population itself will have to be considered when the genetic coefficient of variation is low and the cost of the seed is high, eg $\left(r_{H}-1\right) / t_{H}>0.10$ (fig $1 \mathrm{c}$ ).

$F_{2}$ varieties are justified in specific situations:
- with a relatively low inbreeding depression $(\Delta$ $<0.20)$ and low $\mathrm{CV}$ for hybrids $\left(C_{H}<0.10\right)$ for given $Q$ and $\left(r_{H}-r_{0}\right) / t_{H}$ ratios (fig $1 \mathrm{~b}$ );

- with a relatively low inbreeding coefficient $(\Delta<$ $0.20)$ and low $Q$ ratio $(Q<1.3)$ for given $C_{H}=$ 0.10 and $\left(r_{H}-r_{O}\right) / \mathrm{t}$ (fig $\left.1 \mathrm{~d}\right)$;

- with a moderate inbreeding depression, $0.20<$ $\Delta<0.40$, and relatively high $\left(r_{H}-r_{0}\right) / t_{H}$ ratio (> 0.12 ) that is to say for relatively expensive $F_{1}$ seed, for given $C_{H}$ and $Q$ (fig 1e). Clearly, the advantage of $F_{2}$ seed in comparison to $F_{1}$ is due to its low cost, which more than compensates for its inferiority in yield.

Those situations in which lines are the best choice are obvious (see fig 1b,d,e): low inbreeding depression $(\Delta<0.20)$ ) for given $Q=1.50$, and $\left(r_{H}-r_{0}\right) / t_{H}=0.10$ (fig $1 \mathrm{~b}$ ) or for given $Q=$ 1.50 and $C_{H}=0.10$ and $\left(r_{H}-r_{o}\right) / t_{H}=0.10$.

As far as the effect of selection intensity is concerned, it appears that as expected an increase in selection intensity narrows the domain of justification of populations. It narrows slightly the domain of justification for $F_{2}$ and enlarges slightly the domain of lines. This is due to the fact that genetic variance among lines is greater than among $F_{2} s$ or $F_{1} s$.

In conclusion, it appears that the 4 types of varieties considered here can be justified in certain situations determined by genetic $\left(\Delta, C_{H}, \sigma_{L}\right)$ $\left.\sigma_{H}\right)$ and economic $\left(\left(r_{H}-r_{0}\right) / t_{H}\right)$ parameters. At the beginning of selection the breeding population will never be the best varietal structure due to its heterogeneity. With strong inbreeding depression, single-cross hybrids must be developed; the development of 3-way - or worse - of double crosses can decrease the advantage of

Table II. Condition for the superiority (from the farmer's point of view) of a given type of variety.

$F_{1}$ hybrids $>$ population

$F_{2}>$ population

$F_{1}>F_{2}$

$F_{1}>$ lines

Lines $>F_{2}$

Lines $>$ population

Certified lines $(c)>$ non-certified lines $(n c)$

$$
\begin{aligned}
& i C_{H}>\left(r_{H}-r_{0}\right) / t_{H} \\
& i C_{H}>\Delta / 2+\left(r_{F_{2}}-r_{P}\right) / t_{F_{2}}(3) \\
& \Delta 2>\left(r_{H}-r_{F_{2}}\right) / t_{H}(1) \\
& \text { or } \Delta / 2+i C_{H}>\left(r_{H}-r_{F_{2}}\right) / t_{H}+i C_{F_{2}}(2) \\
& \Delta>i C_{H}(Q-1)+\left(r_{H}-r_{L}\right) / t_{H} \\
& i(Q-1) C_{H}>\Delta / 2+\left(r_{L}-r_{F_{2}}\right) / t_{L}(3) \\
& i Q C_{H}>\Delta+\left(r_{L}-r_{P}\right) / t_{L} \\
& \Delta_{C}>\left(r_{C}-r_{n c}\right) / t
\end{aligned}
$$

(1) with the $F_{2}$ derived from the $F_{1} ;(2)$ with arbitrary $F_{2} ;(3)$ assuming $\sigma_{\mathrm{F}_{2}}=\sigma_{H}$. 

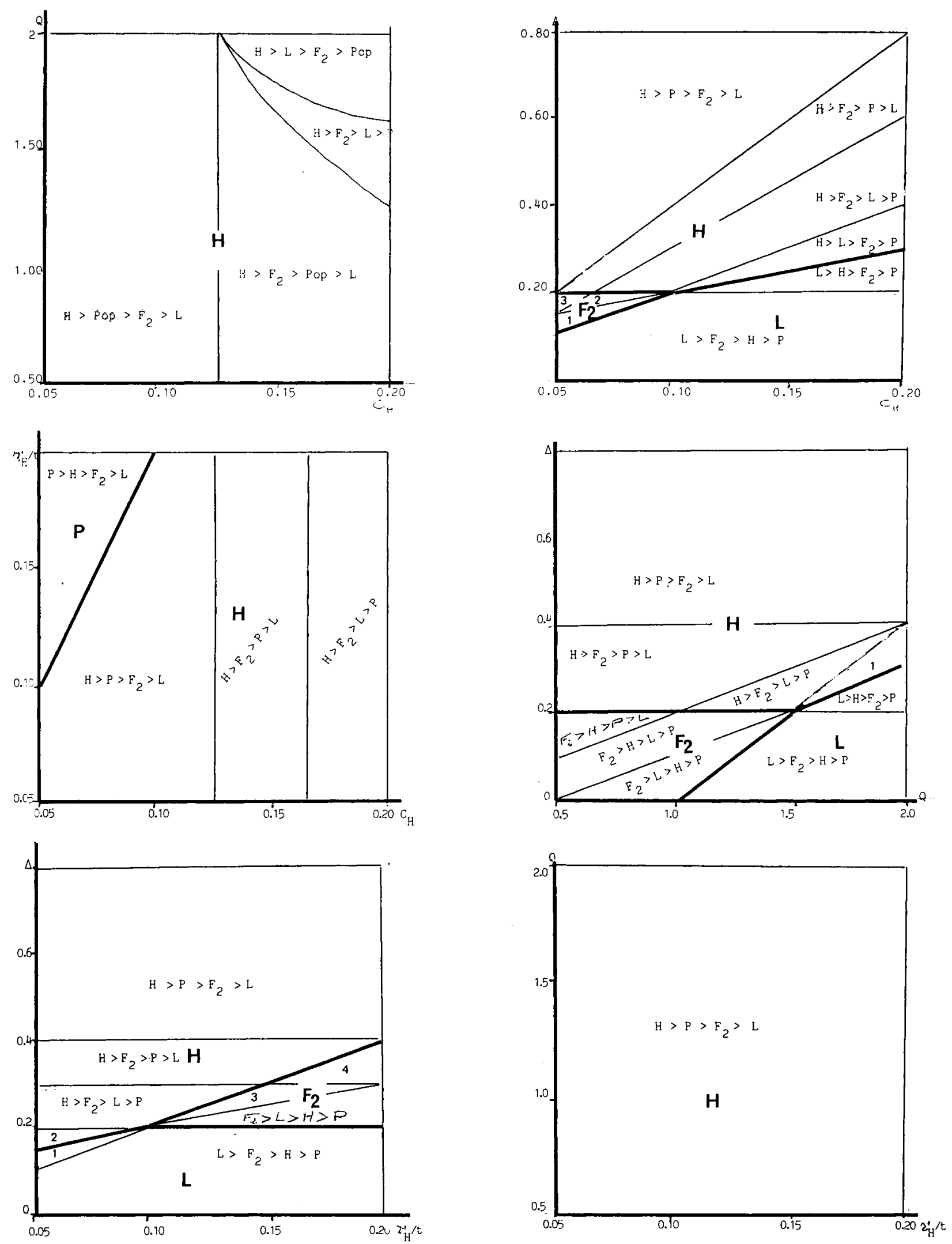

Fig 1. a-f. Superiority domains of a varietal type according to parameters. $Q, C_{H}, \Delta,\left(r_{H}-r_{0}\right) / t_{H} r_{H}^{\prime} / t(H$ : Single-cross hybrids, $\mathrm{P}$ : population, L: lines). a. $f\left(Q, C_{H}\right), \Delta=0.50,\left(r_{H}-r_{0}\right) / t_{H}=0.10$. b. $f\left(\Delta, C_{H}\right), Q=1.50,\left(r_{H}-r_{0}\right) / t_{H}=0.10$. (1) $\mathrm{F}_{2}>\mathrm{L}>\mathrm{H}>\mathrm{P} ;(2) \mathrm{F}_{2}>\mathrm{H}>\mathrm{L}>\mathrm{P}$; (3) $\mathrm{F}_{2}>\mathrm{H}>\mathrm{P}>\mathrm{L}$. c. $f\left(r_{H}-r_{0}\right) / t_{H}, C_{H}, \Delta=0.50, Q=1.50$. d. $f(\Delta, Q), C_{H}=0.10,\left(r_{H}-r_{0}\right) / t_{H}=0.10 .(1) \mathrm{H}>\mathrm{L}>\mathrm{F}_{2}>\mathrm{P}$. e. $\left\{\Delta,\left(r_{H}-r_{0}\right) /\right.$ $\left.t_{H}\right], C_{H}=0.10, Q=1.50$. (1) $\mathrm{L}>\mathrm{H}>\mathrm{F}_{2}>\mathrm{P}$; (2) $\mathrm{H}>\mathrm{L}>\mathrm{F}_{2}>\mathrm{P}$; (3) $\mathrm{F}_{2}>\mathrm{H}>\mathrm{L}>\mathrm{P}$; (4) $\mathrm{F}_{2}>\mathrm{H}$. $t . f\left(Q_{,},\left(r_{H}-\mathrm{r}_{0}\right) / \mathrm{t}_{H}, C_{H}=0.10, \Delta=0.50\right.$. For $i=2$, the domain of justification of 1 type of variety over the 3 other types is delimited by thick boundaries and the name of the justified type is written in bold face. Thick broken lines correspond to such boundaries with a selection intensity of 2.5. Thin boundaries delimit elementary domains in which the rank of the type of variety is given. Clearly some combinations of parameters may be unrealistic. 
hybrids vs population, except when their seed cost is very low as opposed to single crosses. With moderate to low inbreeding depression, $\mathrm{F}_{2} \mathrm{~s}$ or lines will be the best type of varieties.

The question of what happens with selection can now be examined. The 4 "varietal structures" ought to be compared at the same level of breeding effort. It will then be necessary to compare:

- the population improved for its per se value;

- single-cross hybrids derived from a population improved for its combining ability, and singlecross hybrids derived from the population improved for its per se value;

- lines derived from a population improved for its line-value (Gallais, 1979, 1988, 1990b), ie for the average value of the lines that can be derived from it, and lines derived from the population improved for its per se value.

It seem that in the relatively short to medium term, the best strategy will generally be the breeding method adapted to the type of variety that appears to be the best when beginning selection. In the medium to long term, with the decrease in variance due to selection, it could be a waste of effort to develop narrow-based varieties, hybrids or lines. In practice, however, recurrent selection is not a closed but an open system, as a consequence of which the decrease in variability within the population can be maintained at a very slow rate. The difference between the per se value of the population improved for its per se value and the best hybrids derived from the population improved for its combining ability will decrease, but for a long time an advantage for hybrids will remain even if there is no overdominance.

From the genetic point of view, in a closed system and in the absence of overdominance (but with favorable dominance), long-term selection will lead to a population near homozygosity, and therefore hybrids and lines will be equivalent. With partial dominance, no dominance, or with some recessive favorable genes, it will theoretically possible in the very long term to derive lines (by an appropriate breeding method, such as SDHRS Gallais, 1988) that will be superior to single crosses between unrelated lines. This, however, would be a very long task (100-200 yr for maize?) due to the large number of loci involved and to the phenomenon of linkage simulating overdominance (Gallais and Fouilloux, 1988; Gallais, 1989). In fact, single-cross hybrids remain the fastest way of accumulating the maximum number of favorable dominant genes in the same genotype. To further refine the discussion, it would be useful to include comparisons of the relative time necessary to achieve the same levels in yield using the 2 different methods. This would, however, involve assumptions: a) on the rate of gain in recurrent selection vs the time spent in developing first lines from the population, then hybrid varieties from these lines; b) on the progress of selection obtained through continued recurrent selection of the population during this time; c) on expected maximum deviations from the population mean of lines extracted from the population; such assumptions could be so tentative as to be worthless, unless made specifically vis à vis the situation of a specific breeding company dealing with specified populations.

Incidentally, Berlan's claims that it would have been possible in 1922 to adopt population breeding approach (by public research), rather than that of hybrid varieties (by private companies) as being more "farmer friendly" are based on the false assumption that knowledge available today on the efficiency of recurrent selection was available at that time: this is not true, and the poor success of ill-conceived mass selection, and worse of the "corn ear contests", as evidenced by early results from the trial network set up by the USDA around 1915, lead people to believe that population breeding has no future.

Finally, it is difficult to eliminate the contribution of overdominance. Indeed there is a little clear in vivo evidence of such a phenomenon. But the absence of a clear demonstration of it does not imply that it does not exist, as Berlan assumes. Recent results of Leonardi et al (1990) seem to show that marginal overdominance will be very general: at a given time in a given organ, the heterozygote at a locus may be no better than homozygotes, but, at the level of the plant, and over its whole lifespan, due to changes in the direction of dominance according to the internal environment, heterozygosity will be at an advantage. This could be a general property of the diploid or the autopolyploid stage.

Although when heterosis is large, single-cross hybrids remain the fastest way to accumulate favorable dominant genes (recessives have to be fixed in both parents); they represent at the same time the varietal structure that can best stimulate genetic advance, as the farmer has to renew his seed each year, thus incorporating the latest gain in cultivation, and at the same time funding the search for such gain. This may 
partially explain why genetic advance in France is larger for maize than it is for wheat. As compared to the use of seed from the improved population, buying new $F_{1}$ seed is expensive but remains profitable for the farmer and will remain so as long as their larger yield more than compensates for such an investment.

\section{REFERENCES}

Beal WJ (1880) Indian corn. Rep Michi St Board Agric 19, 279-289

Berlan JP (1983) L'industrie des semences, économie et politique. Econ Rur 158, 18-28

Berlan JP (1987) Recherche sur l'économie politique d'un changement technique. Les mythes du maïs hybride. Thèse doctorat, Univ Aix-Marseille

Berlan JP, Lewontin R (1986) Breeder's rights and patenting life-forms. Nature 322, 785-788

Bogue AG (1986) Changes in mechanical and plant technology: The corn belt, 1910-1940. J Econ Hist 43, 1-25

Duvick ND (1974) Continuous backcrossing to transfer prolificacy to a single-eared inbred line of maize. Crop Sci 14, 69-71

Fitzgerald D (1986) Tradition and innovation in agriculture: a comparison of public and private development of hybrid corn. In: The Agricultural Scientific Enterprise (L Busch, WB Lacy, eds) 175-185

Gallais A (1979) Le concept de valeur en lignées et son utilisation possible en sélection. Ann Amélior Plantes 29, 1-22

Gallais A (1988) A method of line development: the single doubled haploid descent recurrent selection. Theor Appl Genet 75, 330-332
Gallais A (1989) Théorie de la Sélection en Amélioration des Plantes. Masson, Paris, $588 \mathrm{p}$

Gallais A (1990a) Determination of the optimum number of parents for synthetics. Theor Appl Genet 79 , 417-421

Gallais A (1990b) Quantitative genetics of doubled haploid populations. Genetics 124, 199-206

Gallais A (1992) Pourquoi faire des variétés synthétiques ? agronomie 12, 601-622

Gallais A, Fouilloux G (1988) Contribution of quantitative genetics, selection theory and simulation studies to the choice between lines and hybrids. In: Proc Eucarpia Sect "Biometrics in Plant Breeding". Norw St Agric Res Stat, AS, 23-35

Hallauer AR, Miranda JB (1981) Quantitative Genetics in Maize Breeding. lowa St Univ Press, Ames IA, $486 \mathrm{p}$

Jones DF (1918) The effects of inbreeding and cross breeding on development. Conn Agric Exp Stat Bull 207, 1-100

Leonardi A, Damerval C, Hébert $Y$, Gallais A, de Vienne $D$ (1991) Association of protein amount polymorphism among maize lines with performances of their hybrids. Theor Appl Genet 82, 552-560

Shull GH (1908) The composition of a field of maize. Am Breeder's Assoc Rep 4, 269-301

Rives M (1954) Le système de reproduction du colza. Sa signification du point de vue de la théorie polygénique de l'hérédité des caractères quantitatifs. Ann Amélior Plantes 4, 21-31

Sprague GF (1980) The changing role of the private and public sectors in corn breeding. In: Rep 35th Ann Corn Sorghum Res Conf 35, 1-9

Zirkle C (1952) Early ideas on inbreeding and crossbreeding. In: Heterosis (Gowen JW, ed) lowa State Coll Press, Ames IA, 1-13 